\title{
W COATINGS DEPOSITED ON CFC TILES BY COMBINED MAGNETRON SPUTTERING AND ION IMPLANTATION TECHNIQUE
}

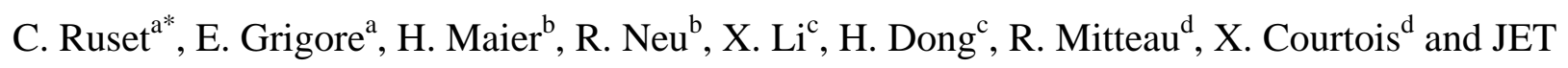
EFDA contributors

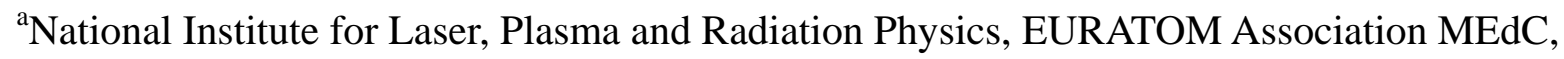
Bucharest-Magurele, PO Box MG-36, Code 077125, Romania

${ }^{\mathrm{b}}$ Max-Planck-Institut für Plasmaphysik, EURATOM Association, 85748 Garching, Germany

${ }^{\mathrm{c}}$ The University of Birmingham, School of Engineering, Edgbaston, Birmingham B15 2TT, UK ${ }^{\mathrm{d}}$ EURATOM Association CEA, Cadarache, DSM/DRFC, Saint Paul Lez Durance, France

PACS Numbers: 62.20.Mk, 68.60.-p, 68.60.Dv,81.15.-z

\begin{abstract}
Combined Magnetron Sputtering and Ion Implantation (CMSII) is a deposition technique involving simultaneously magnetron sputtering and high energy ion bombardment of the coating during its growth. A high voltage pulse discharge $(\mathrm{U}=40 \mathrm{kV}, \tau=20 \mu \mathrm{s}, \mathrm{f}=25 \mathrm{~Hz})$ is superposed over the magnetron deposition and by this way, positive ions are accelerated to the components to be coated, bombarding initially the substrate and then the coating itself. In the framework of the ITER-like Wall Project this method was applied to produce nanostructured W coatings on the CFC (Carbon Fibre Composite) substrate. These coatings have been characterized in terms of
\end{abstract}


adhesion, thickness, structure and resistance to high thermal loads (up to $23.5 \mathrm{MW} / \mathrm{m}^{2}$ ). Based on the results of these tests, which are presented in this paper, CMSII technology was selected for coating about 1,100 tiles with $10 \mu \mathrm{m}$ tungsten layer for the JET first wall and divertor.

* e-mail: ruset@infim.ro 


\section{Introduction}

The material choice for the ITER reactor, in particular for the first wall (Plasma Facing Components - PFC) is of great importance and a big responsibility for the specialists working in this field. The PFC should operate under a very aggressive environment involving intense irradiation and particle bombardment (X-ray, gamma, neutrons, ions, neutral, electrons) [1]. The surface temperature can reach $1,073 \mathrm{~K}$, but in particular areas and during transients, this temperature could exceed 2,273 K. The main requirements, which should be fulfilled by the PFC can be summarized as follows: good mechanical properties, very good resistance at high heat cyclic loads, low sputtering yield, lack of sensitivity to chemical sputtering, low tritium retention, low activation under neutron irradiation and low-Z. Under these conditions, there are not too many candidates for PFC. Carbon, in particular CFC, fulfils some requirements, but has high tritium retention. Beryllium is another good candidate, but unfortunately has a low melting temperature $(1,556 \mathrm{~K})$ which limits its thermal resistance. Another candidate is tungsten, which fulfils almost all the above mentioned requirements except that that as a high- $\mathrm{Z}$ element it is able to radiate even at high central plasma temperatures. The experiments carried out with ASDEX Upgrade tokamak, where approx. $36 \mathrm{~m}^{2}$ of the first wall, consisting of CFC and fine grain graphite, was coated with 1 - $3 \mu \mathrm{m} \mathrm{W}$, have shown that this material is a viable candidate for application in a fusion reactor from the viewpoint of erosion and plasma control [1-3]. At the moment, the first option for ITER is a compromise meaning full beryllium main wall with CFC at the strike points and tungsten divertor baffles and dome. In order to test this combination including Be, $\mathrm{W}$ and $\mathrm{W}$ coated CFC tiles, the ITER like Wall project has been launched at JET (Joint European Torus). 
Tungsten coatings with various thicknesses $(0.2-0.5 \mathrm{~mm}$ and 0.5 - $10 \mu \mathrm{m})$ applied on CFC tiles have been considered as a good alternative to bulk $\mathrm{W}$ for particular areas of the wall with a moderate thermal load. Thick coatings are generally produced by vacuum plasma spray (VPS) and chemical vapor deposition (CVD). A great research effort has been performed to manufacture, investigate and test thick W coatings [4-6]. About 200 graphite tiles coated with $0.5 \mathrm{~mm} \mathrm{~W}$ have been installed in the divertor zone of the ASDEX Upgrade tokamak and successfully tested [2,5]. On the other hand, various PVD and CVD techniques have been developed to produce thin W coatings on graphite and CFC substrates. Coatings of $1-4 \mu \mathrm{m}$ have been produced by PACVD on graphite, stainless steel and $\mathrm{Cu}$ substrates using $\mathrm{WF}_{6}$ and $\mathrm{ReF}_{6}$ as reactive gases [7]. Extensive research carried out by $\mathrm{H}$. Maier and his collaborators [8] demonstrated that the maximum successful W coating thicknesses produced on fine graphite substrates by magnetron sputtering was 3 microns, limited by excessive compressive stress. In 2001 six CFC JET divertor tiles were coated with $\mathrm{W}$ marker stripes for erosion/deposition studies. The W coating with a width of $20 \mathrm{~mm}$ and an average thickness of $3.5 \mu \mathrm{m}$ were produced by the DIARC plasma method [9].

In 2005 when the Task Agreement for development of W coating technologies for 2d-CFC tiles was launched in the framework of the ITER like Wall project, there was a significant experience and knowledge about this subject. However, in order to minimize the risk for the project, various PVD, CVD and VPS techniques have been developed and used to coat fourteen sets of identical CFC samples. Three coating thicknesses have been imposed: $4 \mu \mathrm{m}, 10 \mu \mathrm{m}$ and $200 \mu \mathrm{m}$. All the coated samples have been analyzed and tested according to an established program.

In this paper, the CMSII method and its application for W coating of CFC substrates is presented. 


\section{Specific aspects of the Combined Magnetron Sputtering and Ion Implantation technique}

The Combined Magnetron Sputtering and Ion Implantation is a PVD technique, which can be included in the category of plasma immersion techniques as it has been defined by A. Anders in his review paper [10]. The treatment chamber is similar to conventional magnetron sputtering except that the insulation system of the load can sustain $100 \mathrm{kV}$. Three electrical discharges (magnetron discharge, DC bias discharge and high voltage pulse discharge) are superposed during the deposition process. Typically, pulses of 30 to $70 \mathrm{kV}$, with a width of $\sim 20 \mu$ s and a frequency of 25 to $100 \mathrm{~Hz}$ are applied to the load. The plasma ions are accelerated to the load during the high voltage pulses. They strike initially the substrate and then the layer itself during its growth with energies of tens of keV. Details about this technique are given elsewhere [11,12]. The main features of CMSII method can be summarized as follows:

(i) A high densification of the layer. Using a titanium magnetron target, nc- $\mathrm{Ti}_{2} \mathrm{~N} / \mathrm{nc}-\mathrm{TiN}$ nanocomposite coatings with a hardness of 25 - 40 GPa have been obtained. Their structure is featureless, extremely dense and pore-free. TEM analyses have shown crystallites with a size of less than $10 \mathrm{~nm}[13]$.

(ii) The periodical ion bombardment induces also a stress relief at the interface and within the layer [13]. Due to this effect, coatings with a thickness of $10-50 \mu \mathrm{m}$ have been produced.

The CMSII technique has been developed during the last 6 years in order to produce relatively thick (thickness $>10 \mu \mathrm{m}$ ) hard nanocomposite coatings for tooling applications. In the framework of the ITER-like Wall Project the application area of this technique has been extended to W coating of CFC tiles. 


\section{Experimental results and discussions}

\subsection{Deposition}

Prior to coating the real CFC samples, the CMSII technique was optimized using small samples of $40 \times 30 \times 7 \mathrm{~mm}$. All the CFC material has been baked at JET at $673 \mathrm{~K}$. No ultrasonic cleaning has been applied. The samples have been coated in $\mathrm{Ar}$ at a pressure of $7 \cdot 10^{-1} \mathrm{~Pa}$ with a rate of $1.1 \mathrm{~nm} / \mathrm{s}$ at about $573 \mathrm{~K}$. Direct deposition of W on CFC substrate was not successful because of the poor adhesion, and an intermediate layer was needed. Due to the fact that it is not a carbide former and has a high melting temperature, Re has been successfully used as an interlayer by other authors $[7,14]$. In addition, it can act as a diffusion barrier between carbon and tungsten, which impedes the formation of the brittle W-C phase for temperatures below 1,573 K.

In the present research, molybdenum was used as a successfully interlayer, although it is a carbide former like $\mathrm{W}$. The use of Mo as a substrate for $\mathrm{W}$ coatings was previously reported in the literature [15,16], but no one has used Mo as an interlayer for W coating on CFC. A beneficial role of Mo seems to be in connection with the adjustment of the thermal expansion mismatch between CFC and $\mathrm{W}\left(\alpha_{\mathrm{W}}=4-5 \cdot 10^{-6} \mathrm{~K}^{-1} ; \alpha_{\mathrm{CFC}}=10-12 \cdot 10^{-6} \mathrm{~K}^{-1}\right.$ perpendicular to fiber and $0-1 \cdot 10^{-6}$ $\mathrm{K}^{-1}$ parallel to fiber plane; $\alpha_{\mathrm{Mo}}=7.2 \cdot 10^{-6} \mathrm{~K}^{-1}$ ).

During the research phase the deposition parameters have been optimized in order to get the best adhesion of the $\mathrm{W}$ coating to the CFC substrate and the highest thermal resistance.

\subsection{Coating characterization}


Five samples were coated: for four samples the surface was perpendicular to the fiber planes, for the fifth it was parallel to the planes. The W layer was characterized in terms of thickness, adhesion, structure and resistance to high thermal loading by using optical microscopy, SEM, TEM, XRD and other facilities.

\subsubsection{Coating thickness}

CMSII technique was applied to produce W coatings in the range of 9 - $12 \mu \mathrm{m}$. In Fig.1 a micrograph of a W coating of $11 \mu \mathrm{m}$ with a Mo interlayer of $\sim 2 \mu \mathrm{m}$ is shown. The micrograph is taken at a location where the fibers run parallel with the surface and perpendicular to the image plane. A SEM fracture micrograph revealing $\mathrm{W}$ coating and Mo interlayer is shown in Fig.2. As it can be seen, the W coating is very compact with an excellent adhesion to the Mo interlayer.

\subsubsection{Structure}

A TEM analysis of a W coating deposited on CFC substrate by the CMSII under optimized deposition parameters indicates that the grain size is less than $10 \mathrm{~nm}$ (Fig.3). The nano-sized grains possess a preferred orientation of (200) planes parallel to the surface and $\{110\}$ planes perpendicular to the surface. These were evidenced by the strong (200) peak in XRD pattern (Fig.4) and bright diffraction ring of (110) planes in SAED (Selected Area Electron Diffraction) pattern (Fig.3).

\subsubsection{Adhesion}

The adhesion of the $\mathrm{W}$ coating to the CFC substrate was measured by using the pulling-test method. A screw with a surface area of $10^{-4} \mathrm{~m}^{2}$ was stuck to the $\mathrm{W}$ coating using strong epoxy 
glue. After drying, it was pulled up with a displacement speed of $8.33 \cdot 10^{-6} \mathrm{~m} / \mathrm{s}$. The force was recorded with a $20 \mathrm{kN}$ gauge and the specific detaching load was calculated using the fracture area evaluated post-mortem. The average value obtained for 3 experiments was $12.9 \mathrm{MPa}$. This is 96\% of the average value measured for CFC material without coating (13.5 MPa).

\subsubsection{Thermal resistance}

The thermal resistance of the $\mathrm{W}$ coatings was tested in four steps. The first step was carried out with small samples $(40 \times 30 \times 7 \mathrm{~mm})$ during the optimization process of the CMSII technology using a hollow cathode arc discharge, able to produce a power density of approx. $1 \mathrm{MW} / \mathrm{m}^{2}$. The $\mathrm{W}$ coated samples were subjected to this discharge for $60 \mathrm{~s}$ and their temperature reached $1,373 \mathrm{~K}$.

The second step was a thermal screening of a sample with approx. dimensions $80 \times 70$ x 40 mm, in the ion beam GLADIS facility at IPP Garching, Germany. 26 pulses with power densities from $6.0 \mathrm{MW} / \mathrm{m}^{2}$ to $23.5 \mathrm{MW} / \mathrm{m}^{2}$ and duration from $10 \mathrm{~s}$ to $1 \mathrm{~s}$ have been applied. At the highest power density the surface temperature exceeded 2,273 K.

The third step was a cyclic loading of 200 pulses at a power density of $10.5 \mathrm{MW} / \mathrm{m}^{2}$ and duration of $5 \mathrm{~s}$.

The $10 \mu \mathrm{m} \mathrm{W}$ coating deposited by CMSII successfully passed the steps two and three without delamination. Only small cracks with a width of $\sim 1 \mu \mathrm{m}$, oriented perpendicular to the fibers could be detected by SEM analysis. The coating surface and the cross-section images after cyclic loading are shown in Fig. 5 and Fig.1 respectively. As it can be seen the coating is well adherent to the surface even after 200 pulses at GLADIS. 
The last thermal test was performed with the electron beam facility JUDITH at FZ Jülich, Germany at a power density of $350 \mathrm{MW} / \mathrm{m}^{2}$ for $1 \mathrm{~ms}$ on a surface area of 8 x $8 \mathrm{~mm}$. The total number of pulses was 1,000 with a repetition rate of $0.3 \mathrm{~Hz}$. Under these conditions, the coating was partially delaminated.

\section{Summary and Conclusions}

1) Combined Magnetron Sputtering and Ion Implantation, a deposition technique which has been developed for tooling applications, has been successfully applied for W coating of CFC substrates.

2) Five CFC samples with approximate dimensions 80 x 70 x $40 \mathrm{~mm}$ and 80 x 40 x 40 mm were coated with $10 \mu \mathrm{m}$ tungsten. The coatings were characterized in terms of thickness, structure, adhesion and they were tested at high thermal loads.

3) The $10 \mu \mathrm{m}$ nanostructured W coatings deposited by CMSII technology exhibited a superior thermal resistance at high heat fluxes in comparison with other coatings of the same thickness deposited by conventional PVD or CVD techniques. This good performance of the W coatings deposited by CMSII technique might be attributed to the following factors:

- nanostructure of the coating

- introducing of a Mo interlayer which attenuated the mismatch between the thermal expansion coefficients of the CFC and $\mathrm{W}$

- high energy ion bombardment which reduces the internal stress within the coating.

Further investigation is necessary in order to understand the correlation between the coating structure and its performance in terms of thermal resistance to high heat fluxes. 


\section{Acknowledgment}

The work was supported by European Commission and Romanian Ministry for Education and

Research under EURATOM Program (Contract 5/2000-NUC-INT(FUS)/TT12) and

PN-06.36.03.01 


\section{References}

[1] H. Bolt, V. Barabash, W. Krauss, J. Linke, R. Neu, S. Suzuki, N. Yoshida and ASDEX Upgrade Team, Journal of Nuclear Materials 329-333, 66 (2004)

[2] H. Maier, S. Kötterl, K. Krieger, R. Neu, M. Balden and ASDEX Upgrade-Team, Journal of Nuclear Materials 258-263, 921 (1998)

[3] R. Neu et al., Nucl. Fusion 45, 209 (2005)

[4] K. Tokunaga, N. Yoshida, N. Noda, T. Sogabe and T. Kato, Journal of Nuclear Materials 258-263, 998 (1998)

[5] C. Garcia-Rosales et al., Fusion Tech. 32, 263 (1997).

[6] S. Tamura, X. Liu, K. Tokunaga, Y. Tsunekawa, M. Okumiya, N. Noda and N. Yoshida, Journal of Nuclear Materials 329-333, 711 (2004)

[7] A. Cambe, E. Gauthier, J. M. Layet and S. Bentivegna, Fusion Engineering and Design 5657, $331(2001)$

[8] H. Maier, J. Luthin, M. Balden, J. Linke, F. Koch and H. Bolt, Surface and Coatings Technology 142-144, 733 (2001)

[9] S. Lehto, J. Likonen, J. P. Coad, T. Ahlgren, D. E. Hole, M. Mayer, H. Maier and J. Kolehmainen, Fusion Engineering and Design 66-68, 241 (2003)

[10] A. Anders, Surf. Coat. Technol., 156, 3, (2002)

[11] C.Ruset, E.Grigore, Surf. Coat. Technol., 156, 159 (2002)

[12] C.Ruset, E.Grigore, G.A.Collins, K.T.Short, F.Rossi, N.Gibson, H.Dong, T.Bell, Surf. Coat. Technol., 174-175, 698 (2003)

[13] E.Grigore, C.Ruset, K.Short, D.Hoeft, H.Dong, X.Y.Li, T.Bell, Surf. Coat. Technol., 200, 744 (2005) 
[14] K. Tokunaga, T. Matsubara, Y. Miyamoto, Y. Takao, N. Yoshida, N. Noda, Y. Kubota, T.

Sogabe, T. Kato and L. Plöchl, Journal of Nuclear Materials 283-287, 1121 (2000)

[15] S. Tamura, K. Tokunaga and N. Yoshida, Journal of Nuclear Materials 313-316, 250 (2003)

[16] Du Jihong, Li Zhengxiang, Liu Gaojian, Zhou Hui and Huang Chunliang, Surf. Coat. Technol., 198, 169 (2005) 


\section{FIGURE CAPTIONS}

Fig.1 Optical micrograph of a W coating deposited by CMSII after 200 pulses at GLADIS

Fig.2 Scanning Electron Microscopy micrograph of the W coating deposited by CMSII

Fig.3 Transmission Electron Microscopy image and Selected Area Electron Diffraction pattern of the W coating deposited by CMSII

Fig.4 X-Ray Diffraction pattern of the W coating deposited by CMSII

Fig.5 Scanning Electron Microscopy surface image of the coating deposited by CMSII after cyclic thermal loading 


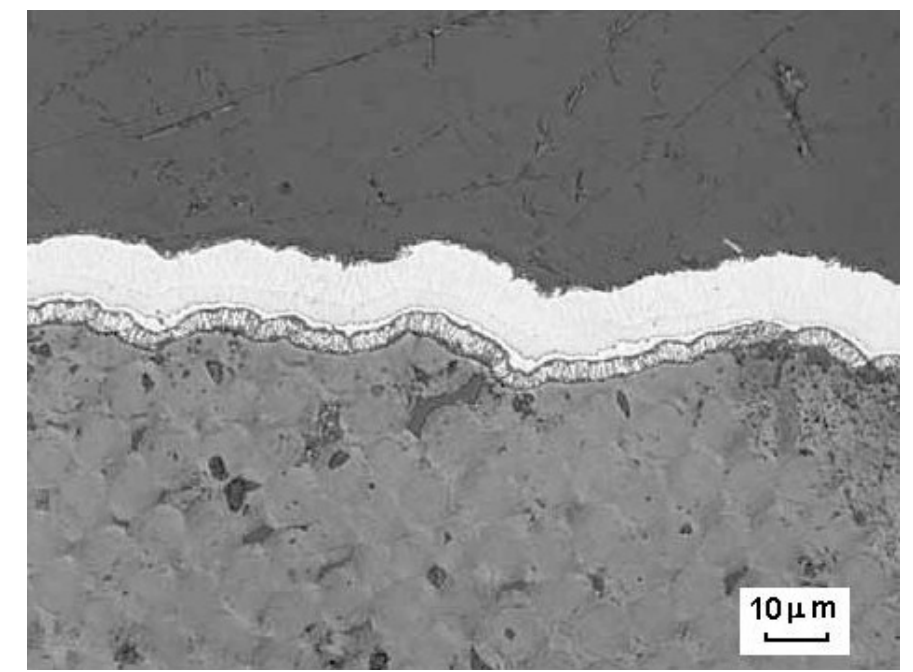

Fig.1 Optical micrograph of a W coating deposited by CMSII after 200 pulses at GLADIS

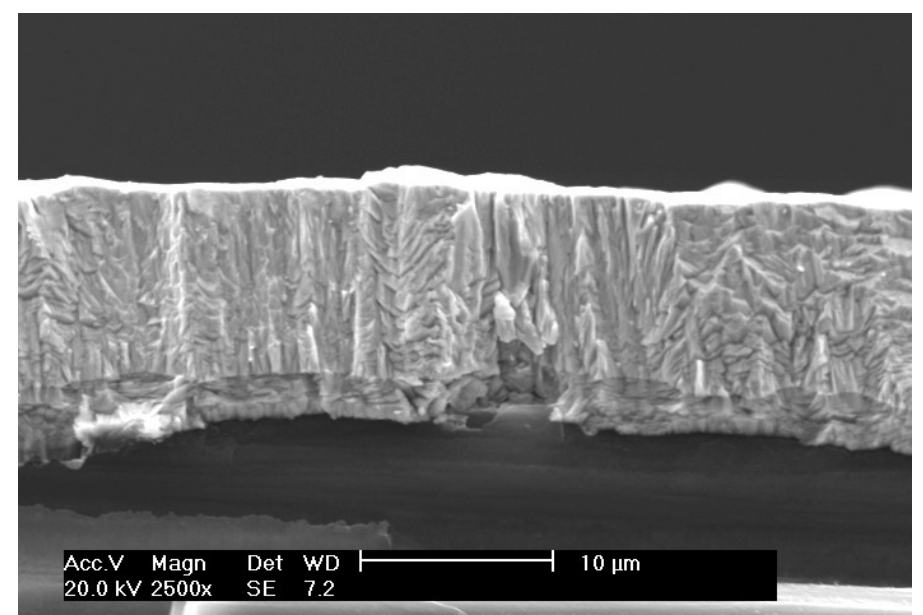

Fig.2 Scanning Electron Microscopy micrograph of the W coating deposited by CMSII 


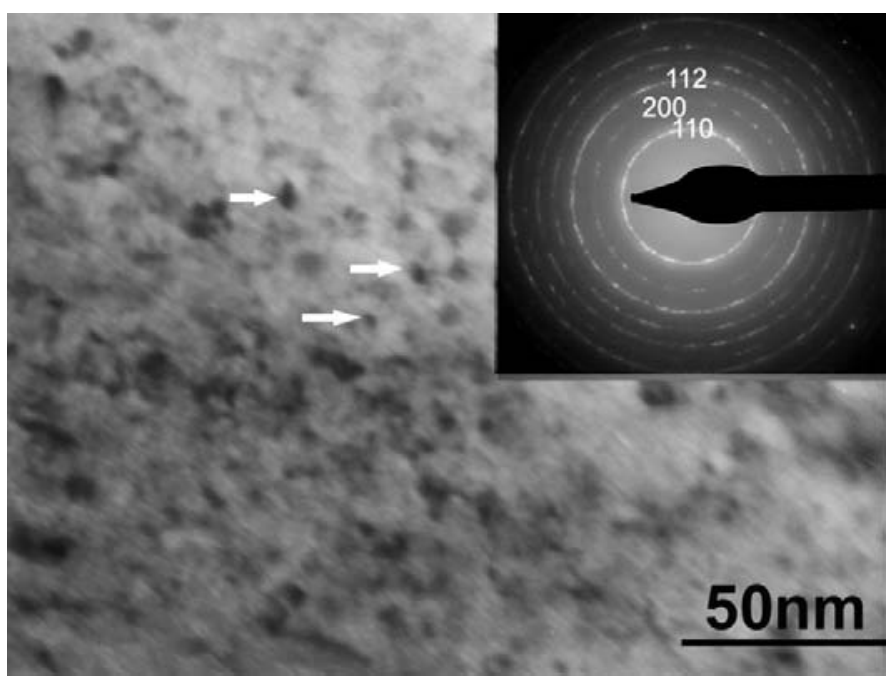

Fig.3 Transmission Electron Microscopy image and Selected Area Electron Diffraction pattern of the W coating deposited by CMSII

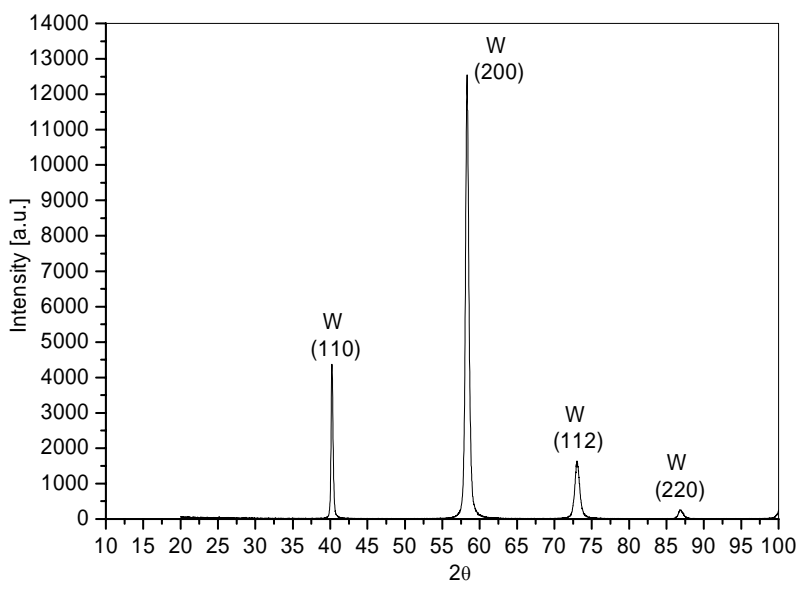

Fig.4 X-Ray Diffraction pattern of the W coating deposited by CMSII 


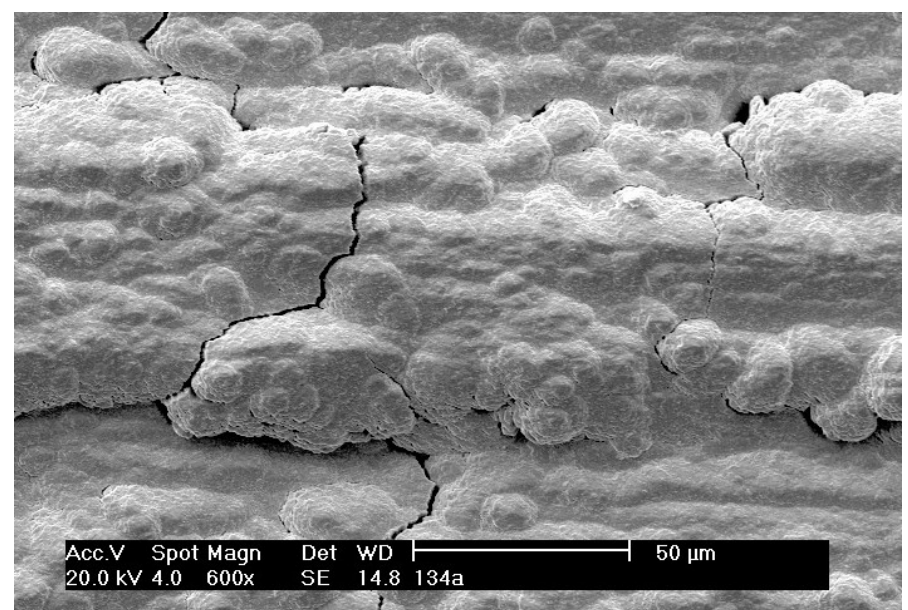

Fig.5 Scanning Electron Microscopy surface image of the coating deposited by CMSII after cyclic thermal loading 